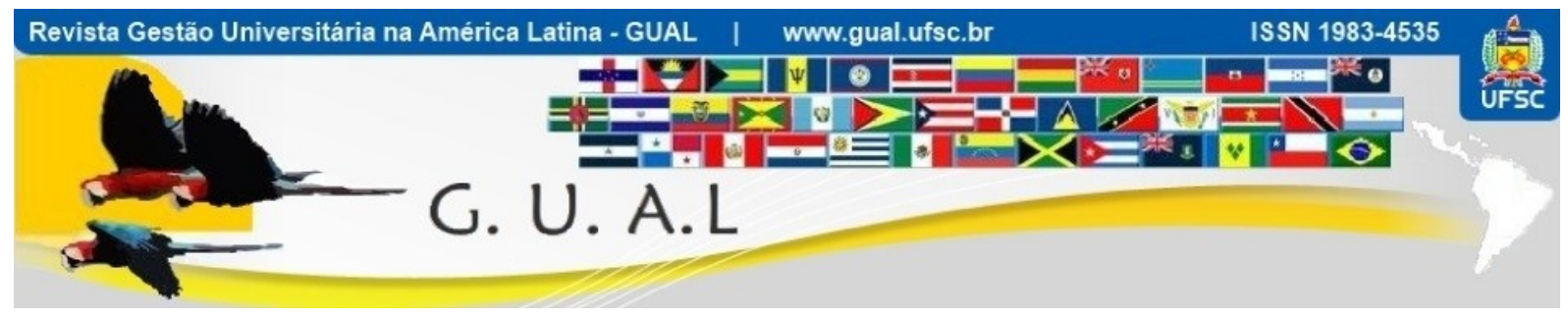

DOI: http://dx.doi.org/10.5007/1983-4535.2012v5n2p196

\title{
ENVELHECIMENTO DA FORÇA DE TRABALHO DO GOVERNO FEDERAL: DESAFIOS PARA A EDUCAÇÃO SUPERIOR PÚBLICA
}

\section{WORKFORCE AGING OF THE FEDERAL GOVERNMENT: A CHALLENGE FOR THE PUBLIC HIGHER EDUCATION}

Júlio Eduardo Ornelas Silva, Mestrando Universidade Federal de Santa Catarina - UFSC

julio.eduardo@ufsc.br

Cláudio José Amante, Doutor Universidade Federal de Santa Catarina - UFSC claudiojosea@yahoo.com.br

Luiz Salgado Klaes, Doutor Universidade Federal de Santa Catarina - UFSC klaes@cse.ufsc.br

Marilda Todescat, Doutora Universidade Federal de Santa Catarina - UFSC marildat@gmail.com

Eduardo Lobo, Doutor Universidade Federal de Santa Catarina - UFSC lobo@cse.ufsc.br

Recebido em 23/dezembro/2011

Aprovado em 08/maio/2012

Sistema de Avaliação: Double Blind Review 


\begin{abstract}
RESUMO
O envelhecimento da população é uma tendência mundial que vem se acelerando desde o século XVIII, a partir da Revolução Industrial. Caracteriza-se por dois fatores primordiais: diminuição da taxa de natalidade e diminuição da taxa de mortalidade. Os países desenvolvidos e amadurecidos socioeconomicamente encontram-se em estágio adiantado no envelhecimento populacional, enquanto os países em desenvolvimento trilham o mesmo caminho. Este artigo objetiva analisar o estágio do envelhecimento da força de trabalho do Ministério da Educação, por meio de pesquisas documentais que retratem essa situação nos últimos dez anos desse órgão público, que possui o maior quantitativo de trabalhadores da União. Os resultados apontam que o estágio do envelhecimento da força de trabalho não está avançado, apesar de as despesas com previdência serem crescentes. No entanto, sob uma perspectiva de longo prazo, para alcançar as metas desejadas pelo governo para a educação superior, serão necessárias mudanças de postura pelos gestores públicos.
\end{abstract}

Palavras-chave: Envelhecimento. Força de trabalho. Educação superior. Universidades.

\begin{abstract}
Population aging is a worldwide trend that has accelerated since the eighteenth century, beginning with the Industrial Revolution. It is characterized by two primary factors: declining birth rate and declining death rate. Developed and socioeconomically mature countries are at an advanced stage in the population aging, while developing countries tread the same path. This article aims to analyze the stage of workforce aging of the Ministry of Education - MEC, through research documents that portray the situation in the last ten years of this public agency that has the largest amount of workers in the Union. The results indicate that the stage of workforce aging of the MEC is not advanced, although the costs of social security are growing. However, under a long-term perspective, to achieve the goals desired by the government for higher education, changes of attitude by public managers are necessary.
\end{abstract}

Keywords: Aging. Workforce. Higher education. Universities. 


\section{INTRODUÇÃO}

O envelhecimento da população é uma tendência mundial que teve início com a Revolução Industrial do século XVIII, na Inglaterra, e que, posteriormente, se estendeu para outros países. A diminuição das taxas de fecundidade e mortalidade são as duas principais características que identificam essa tendência, conforme é apresentado na seção 2 .

As influências que o envelhecimento populacional exercem sobre as organizações apresentam-se de múltiplas formas, seja por meio da força de trabalho, do mercado consumidor ou pelas novas condições sociais que surgem.

Atualmente, o principal desafio encontrado por todos os países é a questão da previdência social, pois as contribuições para as previdências são menores que os desembolsos com aposentadorias, criando-se déficits orçamentários. Isso decorre da diminuição da quantidade de jovens no decorrer das décadas, enquanto a quantidade de idosos aumenta.

No Brasil, os órgãos públicos são as primeiras organizações a experimentarem esse processo, por possuírem peculiaridades em relação às organizações privadas, como terem que arcar com seus próprios orçamentos os desembolsos com as aposentadorias e pensões.

A previdência é um dos fatores do envelhecimento populacional, havendo outros, como o envelhecimento da força de trabalho das instituições, que criam dificuldades na gestão de pessoas a curto e longo prazo, em especial pela fuga de know-how.

É nessa perspectiva que o presente artigo se insere, analisando o envelhecimento da força de trabalho no Ministério da Educação, o órgão público federal com maior quantitativo de trabalhadores. Por meio da análise de documentos oficiais, buscou-se caracterizar o envelhecimento da força de trabalho no MEC, identificar o estágio evolutivo em que esse processo se encontra e apontar as principais consequências que o atual estágio pode acarretar para as metas almejadas pelo governo para a educação superior.

$\mathrm{Na}$ seção seguinte, encontram-se apontamentos teóricos sobre envelhecimento populacional, suas consequências, os agravantes para o serviço público, as alternativas propostas por alguns autores e aspectos conceituais sobre profissionalismo nas universidades públicas, em virtude de a pesquisa tratar sobre o MEC. 


\section{APONTAMENTOS TEÓRICOS}

Esta seção apresenta conceitos teóricos sobre envelhecimento populacional, suas características e breve histórico, para então apontar as consequências de sua existência, bem como elenca alguns tratados sobre a administração pública brasileira e o profissionalismo nas universidades públicas federais brasileiras.

\subsection{O envelhecimento populacional}

O envelhecimento da população é uma tendência mundial, segundo Kreling (2010), sendo determinado basicamente por dois fatores: as taxas de fecundidade e as taxas de mortalidade. Kalache (1987) explica que, para uma população envelhecer, a taxa de fertilidade deve diminuir, pois há um menor ingresso de crianças na população, ocasionando, com o tempo, que a proporção de jovens diminua. Se posteriormente ou simultaneamente houver uma diminuição da taxa de mortalidade, o processo de envelhecimento torna-se mais acentuado.

Nasri (2008, p. S4), por sua vez, não atribui o processo de envelhecimento populacional a ambos os fatores, mas apenas à diminuição da taxa de fecundidade:

Ao contrário do que se imagina comumente, o processo de envelhecimento populacional resulta do declínio da fecundidade e não do declínio da mortalidade. Uma população torna-se mais idosa à medida que aumenta a proporção de indivíduos idosos e diminui a proporção de indivíduos mais jovens, ou seja, para que uma determinada população envelheça, é necessário haver também uma menor taxa de fecundidade.

Para Ramos, Veras e Kalache (1987), a diminuição das taxas de fecundidade ocorre principalmente em virtude da limitação do modo de vida das famílias nos grandes centros urbanos, em especial com um contexto de crise econômica, somado a uma incorporação da população feminina à força de trabalho e à disponibilidade de contraceptivos. A queda das taxas de mortalidade, por sua vez, ocorre quando há um melhoramento do saneamento básico nos centros urbanos e o avanço da medicina para diagnóstico e tratamento de enfermidades. Como exemplo, um brasileiro nascido durante a Segunda Guerra Mundial possuía como expectativa de vida 39 anos, ao passo que em 2010 essa idade passou a ser de 73 anos (IBGE, 2010). 
O envelhecimento populacional é uma tendência que, de acordo com Nasri (2008), começou na Europa e acentuou-se com a Revolução Industrial, esta caracterizada pela industrialização e o consequente aceleramento da urbanização das sociedades, proporcionando melhores condições sociais e de saneamento. Na tabela 1, é possível verificar a evolução do crescimento demográfico na Grã-Bretanha no século XVIII, concomitante ao desencadeamento da Revolução Industrial.

Tabela 1 Crescimento demográfico na Grã-Bretanha no século XVIII

\begin{tabular}{cc}
\hline Ano & População (em milhões de habitantes) \\
\hline 1701 & 6,9 \\
1751 & 7,4 \\
1781 & 8,9 \\
1801 & 10,7 \\
1821 & 14,2 \\
\hline
\end{tabular}

Fonte: Adaptado de Schmidt (2002).

Recentemente, a existência de uma população envelhecida é uma realidade nos países desenvolvidos, em contraste com os países em desenvolvimento. A explicação é histórica, sendo que nas nações desenvolvidas a industrialização ocorreu primeiro e, com ela, a urbanização, ao contrário dos países em desenvolvimento, cuja industrialização se acelerou apenas na segunda metade do século XX. Dados apresentados por Ramos, Veras e Kalache (1987) e relacionados na tabela 2 evidenciam a realidade atual.

Tabela 2 Taxa de crescimento dos idosos na Inglaterra e no Brasil

\begin{tabular}{ccc}
\hline Período & Inglaterra & Brasil \\
\hline 1900 a 1960 & $230 \%$ & $497 \%$ \\
1960 a 2025 & $80 \%$ & $917 \%$ \\
\hline
\end{tabular}

Fonte: Adaptado de Ramos, Veras e Kalache (1987).

De acordo com tabela 2, durante o século XX e início do século XXI, a taxa de crescimento dos idosos na Inglaterra diminuiu de $230 \%$ para $80 \%$, evidenciando que sua população estava em fase de envelhecimento desde a Revolução Industrial do século XVIII, com as taxas de fecundidade diminuídas. Nesse país, o processo de envelhecimento populacional já estava consolidado findo o século XX.

Ainda de acordo com a tabela 2, no mesmo período, o Brasil aumentou a taxa de crescimento dos idosos de $497 \%$ para $917 \%$, sendo que a taxa de fecundidade foi elevada no período, pois a industrialização e a consequente urbanização somente se concretizaram a 
partir da segunda metade do século XX, concomitante a uma melhor qualidade de vida, que prolonga a expectativa de vida da população.

Ramos, Veras e Kalache (1987) concluem que foi somente nas últimas décadas que os países em desenvolvimento vêm apresentando um progressivo declínio nas suas taxas de mortalidade e de fecundidade, promovendo um envelhecimento real da base demográfica. Nasri (2008) observa que, na América Latina, o momento histórico foi diferenciado, pois enquanto na Europa aconteceram significativos desenvolvimento sociais e de aumento de renda, na América Latina o processo de urbanização ocorreu sem alteração da distribuição de renda. Kreling (2010) e Camarano e Pasinato (2005) também afirmam que nos países desenvolvidos o envelhecimento ocorreu em um cenário socioeconômico favorável, ao passo que nos em desenvolvimento o processo encontra-se em meio a uma conjuntura recessiva e a uma crise fiscal.

Nasri (2008) comenta o que seria o envelhecimento dentro da própria população idosa, visto que, se em 2008, no mundo, os idosos com mais de 80 anos representavam $17 \%$ na população acima de 65 anos, em 2050 estima-se que representarão cerca de $28 \%$.

\subsection{Consequências do envelhecimento populacional}

Camarano e Pasinato (2005) reconhecem que, apesar de o envelhecimento da população ter sido uma conquista social do século XX, ele trouxe consigo grandes desafios para as políticas públicas, pois ocorre em meio a uma ampla lista de questões sociais não resolvidas. Com a baixa da fecundidade dos países em desenvolvimento, Ramos, Veras e Kalache (1987) acreditam que em um tempo relativamente curto haverá uma transformação drástica na estrutura etária sem que tenha ocorrido uma real melhoria das condições de vida advindas de conquistas sociais adquiridas para a maioria da população.

$\mathrm{O}$ aumento do número de pessoas idosas na população traz às discussões duas linhas de pensamento, segundo Camarano e Pasinato (2005). A primeira considera esse aumento uma ameaça ao futuro das economias, aumentando o peso econômico sobre a população jovem; a segunda linha, por sua vez, considera que a população idosa pode contribuir significativamente para o desenvolvimento econômico e social, por ser uma fonte viva de recursos.

De fato, o segundo pensamento tem prevalecido, quando observa-se que o tempo para as aposentadorias está aumentando. Em 2002 foi realizado em Madri, na Espanha, a Segunda 
Assembleia Mundial sobre o Envelhecimento, organizada pelas Nações Unidas. Camarano e Pasinato (2005, p. 259) explicam que a Assembleia considera que a população idosa “[...] pode significar uma acumulação de capital humano, social e econômico. Em termos de políticas, pode-se pensar na adequação das instituições para que o crescimento da população idosa seja um elemento propulsor do bem-estar da sociedade.”.

A participação das pessoas idosas no mercado de trabalho depende das suas habilidades e de sua vontade de trabalhar. Camarano e Pasinato (2005) apontam fatores facilitadores nesse processo, como o estado de saúde dessa população, sua capacidade funcional, as condições do mercado de trabalho, além da legislação vigente. A Eurofound (2008) elaborou o quarto Inquérito Europeu sobre as Condições de Trabalho - IECT, e discutiu sobre o prolongamento da participação da população idosa no mercado de trabalho europeu.

O IECT demonstrou a obtenção de resultados positivos, mas salientou que, para a manutenção desse progresso, é essencial criar condições necessárias que encorajem os idosos a permanecerem nos seus empregos durante mais tempo e oferecer-lhes oportunidades vantajosas. As principais conclusões do inquérito afirmam que os trabalhadores de mais idade estão bem representados entre os trabalhadores em tempo parcial e em trabalhos temporários.

\subsection{O envelhecimento da força de trabalho no serviço público brasileiro}

A questão do envelhecimento populacional permeia todos os setores, sejam públicos ou privados. No entanto, no setor público as despesas com pessoal são mais significativas, pois, como demonstra Nascimento $(2010$, p. 229), "[...] os gastos com a folha de pagamento de pessoal representam o principal item de despesas de todo o setor público brasileiro.", por serem "[...] o item de maior peso da despesa pública.".

Entre o grupo de despesas com pessoal, no setor público, estão as despesas com inativos e pensionistas, fato que não ocorre no setor privado. Analisando-se os orçamentos dos diversos órgãos públicos, como os ministérios, universidades, fundações ou câmaras do legislativo, verifica-se, além da contabilização das despesas com pessoal ativo, também os aposentados e os pensionistas.

Essa peculiaridade é um agravante da gestão de pessoas no setor público, pois existem limites impostos pela Lei de Responsabilidade Fiscal para esse grupo de despesa. Exemplificando, na União, os gastos com ativos, inativos e pensionistas são fixados em um 
teto de $50 \%$ da receita circular líquida. Isso quer dizer que, em teoria, cada órgão federal deveria despender esse limite com pessoal; se ultrapassá-lo, o Poder Executivo deve fazer um remanejamento com outros órgãos.

Considerando esse quadro em uma perspectiva de longo prazo, o sistema poderá entrar em colapso, visto que "[...] a despesa com pessoal apresenta um componente vegetativo importante, responsável pelo crescimento desse tipo de despesa de forma continuada.", afirma Nascimento (2010, p. 230). Com o passar do tempo, a participação das despesas dos inativos e pensionistas na limitação de 50\% será cada vez maior. Logo, caso o aumento das receitas não acompanhe o mesmo ritmo, as contratações de pessoal na ativa - e, consequentemente, a prestação de serviços públicos - serão prejudicadas.

Costin (2010, p. 179) afirma que

com o agravamento da crise, as correções de salário e as contratações em grandes números tornaram-se um problema fiscal. A conta de pessoal do governo federal cresceu muito e, apesar da importância de se avançar na profissionalização, quando o orçamento está em boa parte comprometido com despesas de funcionalismo, o país não tem como crescer.

Em tempos recentes verificou-se uma elevação nas contratações, em especial no Governo Federal. De acordo com Nascimento (2010, p. 230), "certamente que o aumento da participação da folha de pagamento nas receitas deveu-se [...] à estabilidade econômica e à queda nos índices inflacionários.".

Esse problema sistêmico necessita ser corrigido hoje de modo a não provocar um colapso no futuro, e deve envolver o que as empresas privadas costumeiramente praticam: melhorar a qualidade da gestão com menos pessoas. Não se deve repetir o erro do passado, já que "a falta [...] de uma visão de longo prazo talvez tenha sido o grande erro estratégico [...]." que deu origem ao problema, conforme Nascimento (2010, p. 276). A capacitação dos colaboradores é uma forma de obterem-se bons resultados a longo prazo, pois o aperfeiçoamento beneficiaria o próprio Estado ao oportunizar novos conhecimentos que solucionariam seus problemas.

\subsection{Alternativas para o envelhecimento populacional no setor público}

Uma gestão mais eficiente, eficaz e efetiva, com menos pessoas, deve ser considerada pelo poder público, sob uma perspectiva de longo prazo. A globalização está impondo modificações, de forma que, na atualidade, "[...] seriam necessários funcionários de carreira, 
muito bem formados e aptos a conceber, coordenar e avaliar programas públicos. Trata-se de profissionais com capacidade de gestão de projetos, monitoramento de custos e articulação entre áreas de governo.", explica Costin (2010, p. 154). Deve-se buscar a profissionalização, atraindo e desenvolvendo talentos para que estes façam a formulação, a gestão e a implementação de políticas públicas, além de sua regulação, fiscalização e avaliação.

Juntamente à busca por esses profissionais de carreira, segundo Costin, deve-se também

investir em tecnologias de trabalho que fomentem desburocratização, agilidade e melhores serviços prestados ao cidadão, eliminando etapas desnecessárias no trabalho, evitando competição interburocráticas disfuncional e capacitando times para um uso mais efetivo da tecnologia da informação, inclusive para gestão do conhecimento. (2010, p. 157).

A aplicação de soluções deverá sofrer obstáculos, em especial problemas intangíveis no tocante à cultura brasileira e que permeiam o clima organizacional dos diversos órgãos públicos. O clientelismo, de acordo com Costin (2010, p. 207) "[...] é altamente enraizado na cultura política brasileira, trazendo consigo uma forte tendência à corrupção, opacidade nas relações entre o público e o privado, favoritismo e riscos para investimentos.". O oferecimento de cargos de confiança, de acordo com o autor, aprofunda esse culturalismo, pois o ocupante pode apresentar um desempenho deficiente, ocasionando inclusive hostilidade da população.

De modo geral, para amenizar os problemas das despesas de pessoal, ao se contratar menos e produzir mais, "a evolução [...] passa certamente por fugir de esquemas clientelistas ainda presentes em parte importante dos cargos de confiança dos três poderes, consolidar a profissionalização obtida especialmente no executivo federal e em alguns estados e fazer parcerias inteligentes [...].", como destaca Costin (2010, p. 179).

\subsection{Profissionalismo nas universidades públicas federais}

As questões apresentadas também são encontradas nas universidades, que necessitam em demasiado de pessoas responsáveis pelo ensino, pesquisa e extensão. As universidades, para a execução de suas finalidades, precisam possuir em seu quadro de pessoal profissionais de elevada qualificação, devendo "[...] criar as condições adequadas para que os seus colaboradores, isto é, professores, pesquisadores, técnicos e administradores, possam desenvolver o seu potencial e as suas aspirações num clima de satisfação e interesse 
permanente [...].” (GRILLÓ, 2001, p. 27). Essas condições englobam alguns incentivos que proporcionam aos profissionais o seu desenvolvimento profissional e pessoal, de forma que se sintam satisfeitos com o trabalho que realizam e tenham motivação frente a novos desafios.

Perpassando por essa necessidade de pessoal com elevada qualificação, cabe destacar a barreira cultural que permeia os demais órgãos públicos, como já exposto anteriormente por meio de Costin (2010). Trigueiro (1999, p. 48) afirma que

[...] as principais ameaças dessas instituições não estão "lá fora", mas em seu próprio interior, em suas práticas obsoletas, sua dificuldade em adequar-se a um novo contexto de relações econômicas e sociais, em seu conservadorismo e em diversos problemas - como o corporativismo e o individualismo exarcebado - que esvaziam o potencial inovador e criativo das universidades.

Portanto, as universidades também necessitam rever as práticas da gestão de pessoas, de modo a estarem preparadas para os desafios futuros, em especial praticarem uma gestão aperfeiçoada com menos contratações. Grilló (2001) sugere incentivos como o desenvolvimento pessoal e profissional, que contribuem para chegar ao que se pretende.

\section{METODOLOGIA}

Esta pesquisa teve início em novembro de 2010 e término em dezembro de 2011, na qual procederam-se análises em dezenas de documentos que buscassem retratar o envelhecimento da força de trabalho do MEC na última década. Esses documentos são oficiais, como os orçamentos do Ministério da Educação do período de 2000 a 2010, cujas fontes foram as leis orçamentárias anuais de cada período, bem como os Boletins Estatísticos de Pessoal, disponibilizados pelo Ministério do Planejamento, Orçamento e Gestão.

Com os dados coletados e o auxílio da ferramenta Excel, da Microsoft, foram realizadas comparações entre a força de trabalho da União e a de alguns órgãos públicos federais - dentre eles, o MEC. Após contextualizar-se a força de trabalho do MEC no âmbito federal, analisou-se a série histórica do quantitativo de pessoal desse Ministério, bem como a relação entre as despesas com pessoal e com aposentadorias. Em seguida, levantaram-se algumas informações atuais no que tange à educação superior, para então reconhecer-se que o avanço de alguns indicadores está ameaçado com as perspectivas de aposentadorias no Ministério até 2019.

Considerando essa metodologia de coleta e análise dos dados, a pesquisa é classificada como qualitativa e quantitativa. Sendo esta uma pesquisa documental, consideramos relevante 
a afirmação de Mattar (2008) segundo a qual existem documentos com uma riqueza a ser explorada que nem sempre é levada em consideração pelos pesquisadores - no caso, as leis orçamentárias e os boletins estatísticos de pessoal.

\section{ANÁLISE DOS RESULTADOS}

A Constituição da República Federativa do Brasil de 1988 organiza a União em três Poderes: Legislativo, Judiciário e Executivo. Sob a responsabilidade do chefe do Poder Executivo concentra-se o maior quantitativo de servidores públicos, que podem ser classificados em civis ou militares. Desses, os civis apresentam-se em maior número, distribuídos na própria Presidência, nos Ministérios e em diversos órgãos subordinados ou vinculados aos Ministérios de sua jurisdição.

O Ministério da Educação - MEC, dentre todos os órgãos da União, possui o maior quantitativo de servidores públicos civis, conforme ranking apresentado na tabela 3.

Tabela 3 Quantitativo de Servidores Públicos Civis Ativos em 2010

\begin{tabular}{lccc}
\hline \multicolumn{1}{c}{ Órgão } & Quantitativo & $\begin{array}{c}\text { Participação em } \\
\text { relação à União }\end{array}$ & $\begin{array}{c}\text { Participação em relação } \\
\text { ao Poder Executivo }\end{array}$ \\
\hline União & 1.109 .565 & $100 \%$ & \\
Poder Executivo & 567.808 & $51,17 \%$ & $100 \%$ \\
Ministério da Educação & 215.025 & - & $37,87 \%$ \\
Ministério da Saúde & 102.865 & - & $18,12 \%$ \\
Ministério da Previdência & 39.557 & - & $7,00 \%$ \\
Ministério da Fazenda & 35.380 & - & $6,23 \%$ \\
Ministério da Justiça & 30.969 & - & $5,45 \%$ \\
\hline
\end{tabular}

Fonte: MPOG (2011, p. 33 e 34).

A pesquisa deste artigo se concentrou no Ministério da Educação, que possui o maior quantitativo de servidores públicos civis do Poder Executivo, estando estes distribuídos em órgãos como as Universidades, Institutos Federais, Hospitais Universitários, Fundações, Institutos de Pesquisas, a própria administração interna e outros órgãos de sua jurisdição, somando em 2011 um total de 140 unidades, sendo que aproximadamente 135 destas lidam com a educação superior.

Por convenção, neste artigo são citados os termos força de trabalho e servidores, que devem ser entendidos como servidores públicos civis ativos da União. 


\subsection{Caracterização do envelhecimento da força de trabalho do MEC}

A caracterização do envelhecimento da força de trabalho do MEC passa por um estudo das regras previdenciárias do Brasil, cuja última modificação significativa foi em 2003, pelo Governo, visando atenuar o saldo financeiro negativo decorrente de as contribuições do pessoal da ativa serem menores que os desembolsos com o pessoal inativo e pensionistas. Cabe salientar que no Brasil existem duas formas de previdência: a primeira, geral, à qual pertencem trabalhadores da iniciativa privada, e a segunda, destinada aos servidores públicos. Cada forma possui regras peculiares; no entanto, ambas estão com o saldo financeiro negativo, devendo o Governo suplementar o déficit orçamentário.

A força de trabalho do MEC se enquadra na previdência destinada aos servidores públicos, possuindo como regra a aposentadoria obrigatória do servidor aos 70 anos, ou voluntariamente quando este completa 60 anos de idade e 35 anos de contribuição para homens ou 55 anos de idade e 30 anos de contribuição para mulheres. Caso a aposentadoria ocorra considerando-se apenas a idade, sem computar-se o tempo de contribuição, o servidor poderá se aposentar por idade quando acrescido de mais 5 anos - logo, 65 anos para homens e 60 anos para mulheres. Existem outras regras específicas que diminuem a idade para aposentadoria, como, por exemplo, a aposentadoria por invalidez. Para efeitos da presente pesquisa, consideraram-se apenas as regras citadas em questão.

Sob essas regras previdenciárias apresentadas, o estágio final do envelhecimento da força de trabalho do MEC ocorre aproximadamente a partir dos 55 anos para mulheres e dos 60 anos para homens, período a partir do qual há a possibilidade de serem servidores inativos, e não mais integrantes da força de trabalho.

\subsection{Estágio atual do envelhecimento da força de trabalho do MEC}

A força de trabalho do MEC é diversificada, composta tanto por servidores que iniciaram suas carreiras na década de 1970 quanto por servidores jovens que ingressaram em 2012 nas dezenas de cargos existentes. De acordo com o Ministério do Planejamento, Orçamento e Gestão (MPOG, 2011, p. 41), a idade média dos servidores do Ministério da Educação é de 44 anos. O gráfico 1 apresenta a variação anual da força de trabalho do MEC, em números absolutos e relativos. 


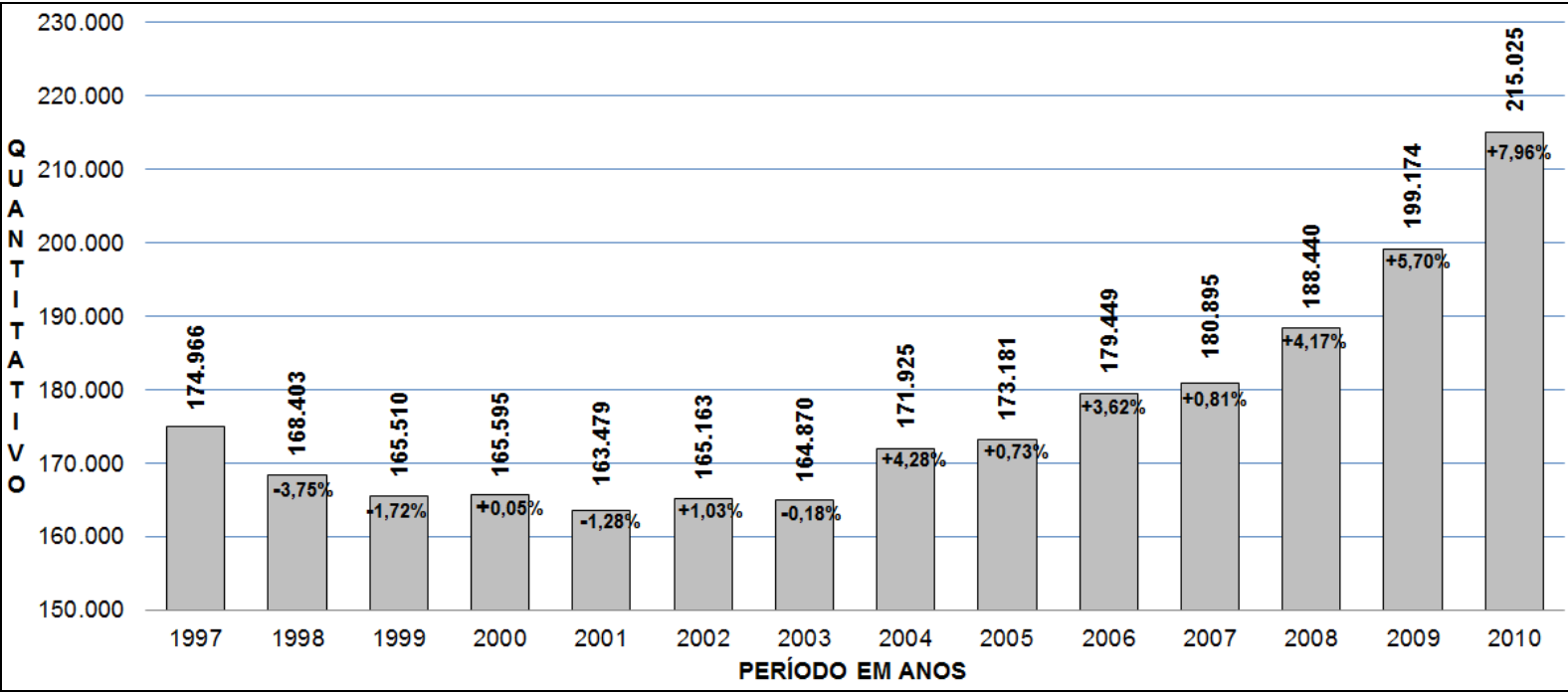

Gráfico 1 Variação anual da força de trabalho do MEC em quantidades e percentagens Fonte: MPOG, 2011, p. 34.

Os dados do gráfico 1 evidenciam que o quantitativo da força de trabalho do MEC apresentou queda de crescimento no período de 1997 a 2003, em 10.096 vagas. De 2004 até 2010 houve significativo crescimento, em 50.155 vagas preenchidas no período. Os anos de 2004, 2008, 2009 e 2010, comparativamente ao período analisado, apresentaram os percentuais de aumento mais expressivos: 4,28\%, 4,17\%, 5,70\% e 7,96\%, respectivamente.

De 1997 a 2003, as vagas ociosas não eram preenchidas automaticamente, em decorrência da política de governo à época quanto à realização de concursos, acarretando a diminuição da força de trabalho do Ministério da Educação. Essa ociosidade decorre principalmente de aposentadorias, mas também de outras razões, como a evasão de profissionais bem formados para a iniciativa privada ou para outros órgãos públicos, em busca de melhores carreiras e salários. A partir de 2004, com a nova equipe do governo federal empossada, o cenário se modificou, pois além da reposição das vagas decorrentes das aposentadorias, criaram-se outras, novas, nos diversos órgãos do $\mathrm{MEC}$, bem como as carreiras tornaram-se mais atrativas e os salários, maiores.

No serviço público brasileiro, os servidores possuem um regime de aposentadoria diferenciado em relação aos trabalhadores da iniciativa privada, o que normalmente proporciona proventos maiores. São computados nos desembolsos com aposentadorias os pagamentos para os servidores inativos e para os beneficiários de pensão. O gráfíco 2 apresenta a evolução anual em bilhões de reais e em percentuais desses gastos no Ministério da Educação. 


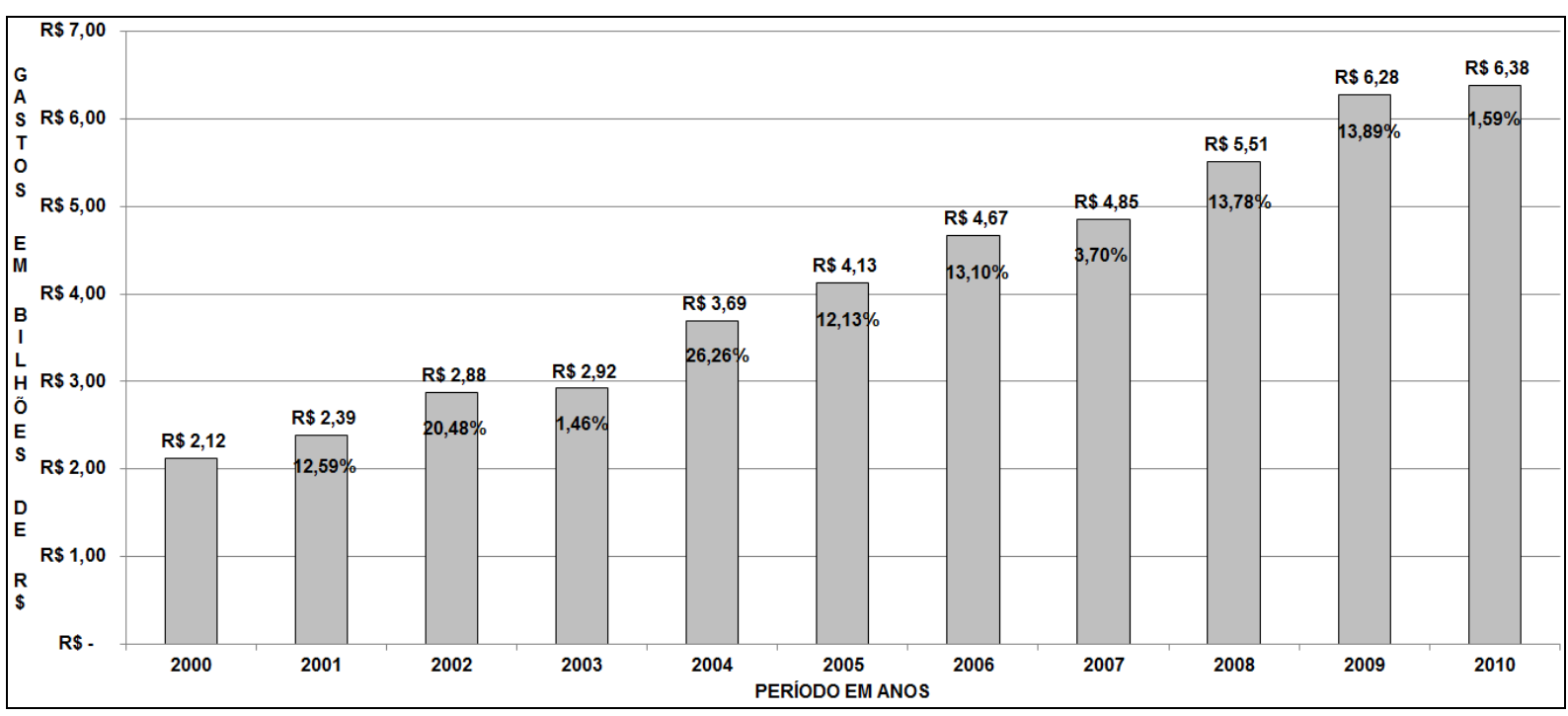

Gráfico 2 Variação anual das despesas do MEC com previdência em bilhões de reais e percentuais

Fonte: Leis orçamentárias anuais de 2000 a 2011.

O desembolso com aposentadorias no MEC, de acordo com o gráfico 2, possui crescimento vegetativo, tendo aumentado em 10 anos mais de 4 bilhões de reais, ou em termos percentuais um aumento superior a $200 \%$ no período. Os maiores aumentos ocorreram de 2002 e 2004 , em $20,48 \%$ e $26,26 \%$ de aumento, respectivamente, em relação aos anos anteriores.

Observa-se que os recursos destinados para aposentadorias pertencem ao orçamento do MEC, sendo inflexíveis quanto ao seu manuseio, pois são obrigações conferidas em lei. Nesse sentido, os gestores devem realizar a gestão do orçamento do Ministério subtraindo os recursos com aposentadorias, para então utilizar o saldo restante para as demais finalidades. A tabela 4 apresenta a evolução em percentuais da participação das despesas com previdência no orçamento do MEC.

$\mathrm{Na}$ tabela 4 a seguir, verifica-se que, apesar de os gastos com aposentadorias serem crescentes (na ordem de $200 \%$ no período de 2000 a 2010), o orçamento do MEC no mesmo período cresceu mais de $302 \%$, o que amortizou a participação percentual das despesas com previdência, ocorrendo inclusive uma diminuição.

A participação percentual das despesas com aposentadorias no orçamento do MEC foi crescente de 2000 até 2005 , apresentando acentuada queda de 2006 a 2010 . A tabela 4 aponta que em 2008, 2009 e 2010 os percentuais de 15,84\%, 13,87\% e 12,53\%, respectivamente, foram menores do que quando se iniciou a década, em 2000, com 16,78\%. 
Tabela 4 Evolução da participação das despesas com previdência no orçamento do MEC

\begin{tabular}{cccc}
\hline ANO & $\begin{array}{c}\text { (A) } \\
\text { Orçamento do MEC } \\
\text { em bilhões de R\$* }\end{array}$ & $\begin{array}{c}\text { (B) } \\
\text { Gastos com Previdência em } \\
\text { bilhões de R\$* }\end{array}$ & $\begin{array}{c}\text { \% de } \\
(\mathbf{B}) /(\mathbf{A}) * *\end{array}$ \\
\hline 2000 & 12,64 & 2,12 & 16,78 \\
2001 & 16,16 & 2,39 & 14,77 \\
2002 & 16,66 & 2,88 & 17,27 \\
2003 & 17,70 & 2,92 & 16,49 \\
2004 & 18,39 & 3,69 & 20,04 \\
2005 & 20,03 & 4,13 & 20,63 \\
2006 & 23,93 & 4,67 & 19,53 \\
2007 & 28,71 & 4,85 & 16,88 \\
2008 & 34,82 & 5,51 & 15,84 \\
2009 & 45,28 & 6,28 & 13,87 \\
2010 & 50,90 & 6,38 & 12,53 \\
\hline \multicolumn{4}{c}{ *Valores arredondados } \\
\multicolumn{4}{c}{ Fonte: Leis orçamentárias anuais de 2000 a 2011. }
\end{tabular}

Analisando os dados da tabela 4 com o gráfico 2, observa-se que os percentuais de participação das despesas com previdência no orçamento do MEC em 2004 e 2005 foram os que apresentaram maiores índices - 20,04\% e 20,63\%, respectivamente -, sendo também nesse período que as despesas com aposentadorias começaram a se acentuar.

Os dados dos gráficos 1 e 2 e da tabela 4 indicam um aumento do quantitativo da força de trabalho do MEC no período de 2004 a 2010, concomitante ao aumento das despesas com aposentadorias. Esse fato só foi possível devido ao incremento significativo da arrecadação de impostos e de recursos no orçamento do MEC, num período em que a economia brasileira apresentou bons momentos.

\subsection{Estágio atual e os desafios para a educação superior nos próximos anos}

Amaral (2003) e Corbucci (2004) afirmam que durante anos houve poucos investimentos no orçamento do Ministério da Educação, em especial no decorrer da década de 1990 e nos anos iniciais do século XXI. À época, o governo transferiu paulatinamente os recursos que seriam destinados à educação superior das Instituições Federais de Ensino (IFEs) para a iniciativa privada, inclusive as responsabilidades pela absorção dos novos universitários. A incapacidade de atender a um número cada vez maior de jovens formados no 
ensino médio que desejavam cursar a graduação em universidades públicas sempre foi uma das dificuldades das IFEs.

Em 2003 houve mudanças na equipe do governo federal e também nas políticas para a educação, o que inclui a educação superior. $\mathrm{O}$ orçamento do MEC aumentou significativamente, conforme demonstrado na tabela 4, e as IFEs, que antes estavam sem investimentos, passaram a ser reestruturadas, inclusive em sua composição de pessoal (o que pode ser confirmado ao analisar-se o gráfico 1). Em contrapartida, essas instituições deveriam quase que dobrar a quantidade de ofertas de vagas no ensino superior.

Como exemplo da mudança de postura do governo para com o cenário em que as universidades se encontravam até meados de 2003, em 2007 foi lançado o Programa de Apoio a Planos de Reestruturação e Expansão das Universidades Federais (REUNI), que objetivava reestruturar as universidades com o incremento de recursos e pessoal, além de estipular a criação de mais vagas no ensino superior, estabelecendo como data final o ano de 2012.

Resultantes dessas políticas de investimentos no MEC desde 2003, foram criadas 14 novas universidades públicas federais, passando-se de 45 para 59 universidades no período de 2004 a 2010. O gráfico 3 apresenta a evolução anual e percentual do número de matrículas e de ingressantes nas IFEs no período de 2001 a 2009.

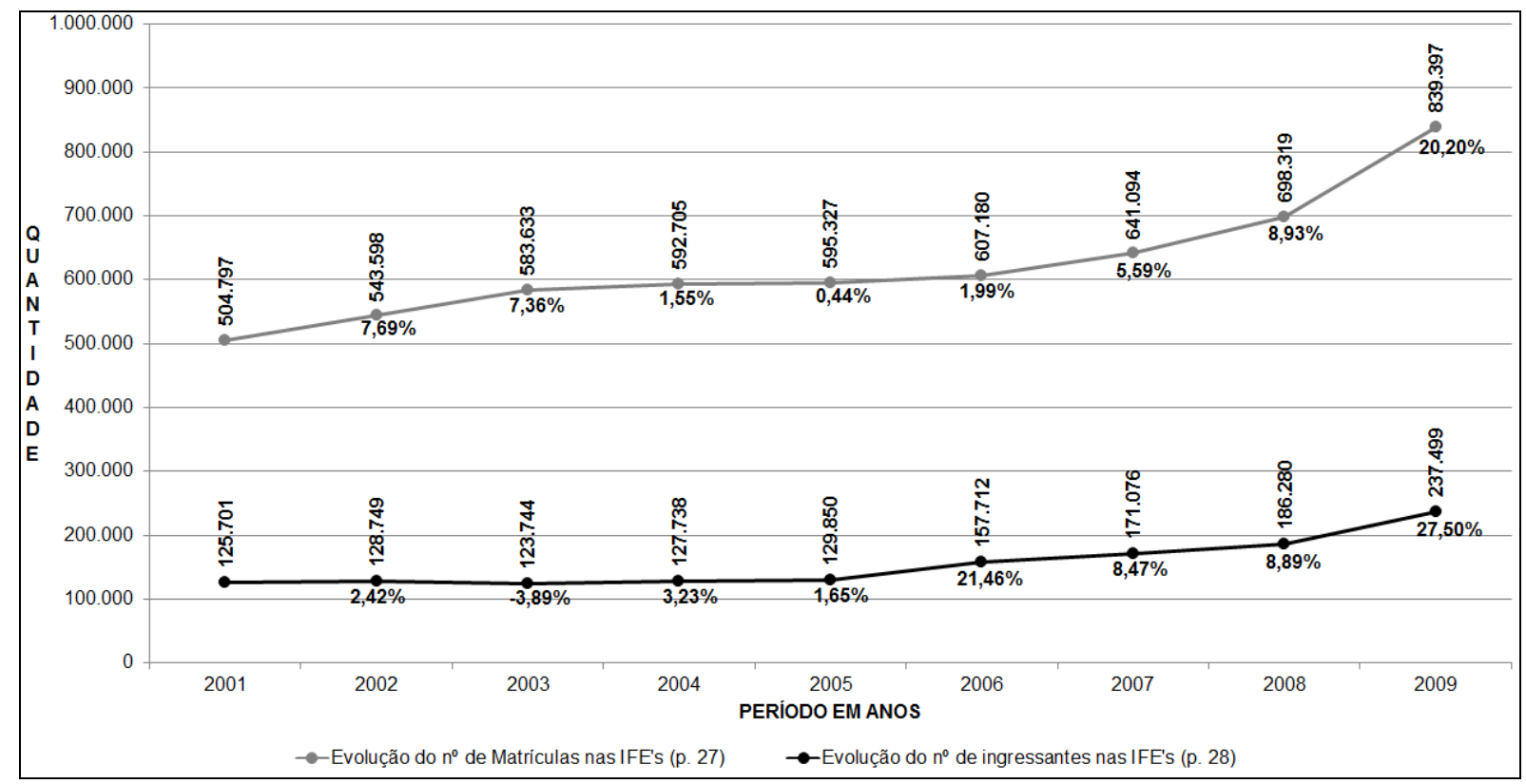

Gráfico 3 Evolução do número de matrículas e de ingressantes nas IFES

Fonte: MEC (2010, p. 28). 
O gráfico 3 indica que o governo federal, a partir dos investimentos realizados, conseguiu aumentar a quantidade de matrículas e de ingressantes por processo seletivo. A evolução no crescimento de ambas variáveis tornaram-se ascendentes a partir de 2006 e 2005 respectivamente, obtendo excelentes resultados em 2009, com 20,20\% e 27,50\% de aumento.

Apesar dos bons resultados alcançados, a quantidade de matrículas existentes nas IFEs continua insuficiente, pois, ao passo que no ano de 2009 houve 839.397 matrículas, a iniciativa privada contava com 4.430 .157 matrículas, ou seja, $14,10 \%$ do total de matrículas para as IFEs e $74,40 \%$ do total de matrículas para as instituições privadas, de acordo com dados do INEP (2010, p. 27).

O Plano Nacional da Educação (PNE) para o período de 2011 a 2020 está em fase de discussão no Congresso Nacional; caso aprovado, estabelece como metas a elevação da taxa bruta de matrícula na educação superior para $50 \%$ e o aumento gradual do número de matrículas na pós-graduação stricto sensu, de modo a atingir-se a titulação anual de 60.000 mestres e 25.000 doutores.

Para alcançar essas metas, o governo deve continuar com o aumento da alocação de recursos no MEC, investindo também em pessoal. A apresentação realizada por Marcos Aurélio Souza Brito, Coordenador Geral de Gestão das IFEs, que era subordinado à Secretaria de Educação Superior do MEC até 2010, fez uma estimativa de aposentadorias até o ano de 2019 e a confrontou com as vagas de concurso previstas para o REUNI até o ano de 2012. Os dados são apresentados na tabela 5 .

Tabela 5 Estimativa de vagas REUNI x Aposentadorias

\begin{tabular}{cccc}
\hline Ano & $\begin{array}{c}\text { Vagas REUNI* } \\
\text { (A) }\end{array}$ & $\begin{array}{c}\text { Aposentadorias } \\
\text { (B) }\end{array}$ & $\begin{array}{c}\text { Diferença } \\
\text { (A-B) }\end{array}$ \\
\hline 2011 & 3.579 & 1.220 & 2.359 \\
2012 & 2.405 & 1.861 & 544 \\
2013 & - & 2.844 & - \\
2014 & - & 3.408 & - \\
2015 & - & 4.560 & - \\
2016 & - & 3.399 & - \\
2017 & - & 5.135 & - \\
2018 & - & 5.478 & - \\
2019 & - & 2.606 & - \\
\hline Total & $\mathbf{5 . 9 8 4}$ & $\mathbf{3 0 . 5 1 1}$ & $\mathbf{2 4 . 5 2 7}$ \\
\hline \multicolumn{4}{c}{} \\
& *O programa REUNI finaliza em 2012. \\
\end{tabular}


Verifica-se na tabela 5 que as novas vagas oportunizadas pelo REUNI acabarão por não serem novas, mas apenas amenizarão as aposentadorias previstas apenas até 2013. A quantidade de aposentadorias previstas até 2019 é expressiva e, se não for considerada a longo prazo, poderá prejudicar o alcance das metas almejadas pelo governo federal.

Nessa análise conjuntural, em que de um lado se propõem metas até 2020 e de outro é exposta a realidade atual dos servidores do MEC, cabe destacar que o governo federal tem pela frente grandes desafios, que passam obrigatoriamente pelo trato com o envelhecimento de sua força de trabalho.

\section{CONCLUSÕES}

O Ministério da Educação é o órgão público federal que possui o maior quantitativo de servidores públicos, sendo possível considerar que sua realidade representa a dos demais órgãos públicos. Ao caracterizar o estágio de envelhecimento populacional ao qual o MEC se encontra, é prudente estabelecer um referencial que permita realizar comparações. Nesse aspecto uma análise das legislações previdenciárias vigentes no país levou à conclusão de que a partir dos 60 anos de idade para homens e 55 anos de idade para mulheres existe a possibilidade de aposentadoria. Essas, portanto, são as idades que podem ser consideradas de estágio avançada para o envelhecimento da força de trabalho no MEC.

Verificou-se que a idade média dos servidores do Ministério da Educação é de 44 anos, e por meio de um simples cálculo, pode-se chegar à conclusão de que, sob uma análise estática, em aproximadamente 10 a 16 anos a média de servidores estará aposentada. A força de trabalho do MEC, no entanto, não é estática; como evidenciaram os dados do gráfico 1, nos últimos 7 anos está ocorrendo a reposição dos aposentados, além do aumento de novas vagas, o que prolonga o estágio do envelhecimento da força de trabalho do Ministério, o que traz certo conforto a gestão de pessoas desse órgão até então.

Conforme se evidencia pelo gráfico 2, as despesas do MEC com a previdência têm crescimento vegetativo, ao passo que a representação percentual deste no orçamento global do Ministério a partir de 2006 foi decrescente, conforme demonstrado na tabela 4. O mesmo período apresentou bons desempenhos na economia brasileira e, considerando as exposições de Nascimento (2010), apresentadas anteriormente, conclui-se que a criação de novas vagas somente tornou-se possível devido ao bom desempenho da economia brasileira, o que trouxe maior arrecadação aos cofres públicos e, assim, a possibilidade de aumento das contratações. 
Com a previsão de aposentadorias até 2019, relatada na tabela 5, os investimentos com pessoal necessitam ser cada vez maiores, sob risco de não se conseguir alcançar as metas estipuladas no Plano Nacional da Educação para o período de 2011 a 2020. Verifica-se também que, apesar dos maciços investimentos que vêm ocorrendo e dos avanços alcançados até então, conforme dados do gráfico 3, o MEC ainda está longe de atender aos anseios da sociedade em questão de abrangência de matrículas, ao representar apenas $14,10 \%$ do total de matrículas em 2009.

Diante dos desafios, sugere-se uma nova forma de gestão que possibilite maior eficiência, eficácia e efetividade com menos pessoas, sem que haja, no entanto, sobrecarga de trabalho. Pode-se pensar em adotar os profissionais de carreiras, conforme proposto anteriormente por Costin (2010), além de criar mecanismos que os capacitem e os motivem, como sugere Grilló (2001). Essa capacitação beneficiará a própria instituição, na medida em que trará novos conhecimentos que solucionem os problemas de Estado. Trata-se, portanto, de um desafio inserido dentro de outro desafio.

Para se alcançar esta proposta, deve-se ter um trato especial com o culturalismo prejudicial que permeia os órgãos públicos, como aponta Costin (2010), e que não foge, via de regra, das universidades, como afirma Trigueiro (1999).

Outra sugestão é criarem-se mecanismos para reaproveitar os aposentados que ainda desejem realizar contribuições à sociedade, em especial aqueles dotados de grande qualificação, como propõem Camarano e Pasinato (2005), criando-se para tanto condições atrativas para o exercício das funções e eliminando-se riscos que os repulsam, como a perda da garantia de aposentadoria. Alterações nas legislações seriam necessárias.

Dessa forma, conclui-se que a força de trabalho do Ministério da Educação está caminhando para um estágio avançado e que, se medidas não forem adotadas atualmente, haverá dificuldades na gestão da educação superior brasileira no futuro.

\section{REFERÊNCIAS}

AMARAL, Nelson Cardoso. Financiamento da educação superior: estado x mercado. São Paulo: Cortez; Piracicaba, SP: Editora UNIMEP, 2003.

BRITO, Marcos Aurélio Souza. Agenda da autonomia: gestão de pessoas. Apresentação de palestra, 2010. Disponível em: <http://www.ufmg.br/prorh/endp/Palestras/Pol\%EDticas \%20do\%20MEC\%20para\%20a\%20Gest\%E3o\%20de\%20Pessoas\%20-\%20Parte\%202\%20 (Marco\%20Aur\%E9lio\%20Souza\%20Brito,\%20Ant\%F4nio\%20Leonel\%20da\%20Silva\%20 Cunha).pdf>. Acesso em: 7 fev. 2011. 
CAMARANO, Ana Amélia; PASINATO, Maria Tereza. O envelhecimento populacional na agenda das políticas públicas. Rio de Janeiro: IPEA, 2005. Disponível em: <www.ipea.gov. br/sites/000/2/livros/idosoalem60/Arq._16_cap_08.pdf-Microsoft $>$. Acesso em: 14 nov. 2010.

CORBUCCI, Paulo Roberto. Financiamento e democratização do acesso à educação superior no Brasil: da deserção do Estado ao projeto de reforma. Revista Educação e Sociedade, Campinas, v. 25, n. 88, p. 677-701, out. 2004.

COSTIN, Claudia. Administração pública. Rio de Janeiro: Elsevier, 2010.

FUNDAÇÃO EUROPÉIA PARA A MELHORIA DAS CONDIÇÕES DE VIDA E DE TRABALHO - EUROFOUND. Condições de trabalho de uma força de trabalho em envelhecimento: resumo executivo. Dublin, Irlanda: Eurofound, 2008. Disponível em: $<$ http://www.eurofound. europa.eu/pubdocs/2008/57/pt/1/EF0857PT.pdf $>$. Acesso em: 6 dez. 2010.

GRILLÓ, Antônio Niccoló. Gestão de pessoas: princípios que mudam a administração universitária. Florianópolis: [s.n.], 2001.

INSTITUTO BRASILEIRO DE GEOGRAFIA E ESTATÍSTICA - IBGE. Indicadores de desenvolvimento sustentável - Brasil 2010. In: Comunicação social, notícia impressa. Rio de Janeiro: IBGE, 2010. Disponível em: <http://www.ibge.gov.br/home/presidencia/noticias/ noticia_impressao.php?id_noticia $=1703>$. Acesso em: 11 jan. 2011.

KALACHE, Alexandre. Envelhecimento populacional no Brasil: uma realidade nova. Cadernos de Saúde Pública, Rio de Janeiro, v. 3, n. 3, p. 217-220, jul/set. 1987.

KRELING, Norma Herminia. O envelhecimento do trabalhador impõe novos desafios às políticas públicas. In: XVII ENCONTRO NACIONAL DE ESTUDOS POPULACIONAIS ABEP, Caxambu/MG, set. 2010.

MATTAR, João. Metodologia científica na era da informática. 3. ed. São Paulo: Saraiva, 2008.

MINISTÉRIO DA EDUCAÇÃO - MEC. Resumo técnico - censo da educação superior de 2009. Brasília: INEP, 2010. Disponível em: <http://www.inep.gov.br/download/superior/ censo/2009/resumo_tecnico2009.pdf $>$. Acesso em: 10 jan. 2011.

MINISTÉRIO DO PLANEJAMENTO, ORÇAMENTO E GESTÃO - MPOG. Boletim estatístico de pessoal, vol. 16, n. 177 (jan. 2011). Brasília: MPOG, 2011. Acesso em: Disponível em: <http://www.servidor.gov.br/publicacao/boletim_estatistico/bol_estatistico _11/Bol177_Jan2011.pdf>. Acesso em: 16 fev. 2011.

NASCIMENTO, Edson Ronaldo. Gestão pública. 2. ed. rev. e atualizada. São Paulo: Saraiva, 2010. 
NASRI, Fabio. O envelhecimento populacional no Brasil. Einstein, v. 6, supl. 1, p. S4-S6, 2008.

RAMOS, Luiz Roberto; VERAS, Renato P.; KALACHE, Alexandre. Envelhecimento populacional: uma realidade brasileira. Revista Saúde Pública, São Paulo, v. 21, n. 3, p. 211 224, 1987.

SCHMIDT, Mario Furley. Nova história crítica: moderna e contemporânea. São Paulo: Nova Geração, 2002.

TRIGUEIRO, Michelangelo Giotto Santoro. Universidades públicas: desafios e possibilidades no Brasil contemporâneo. Brasília: Editora Universidade de Brasília, 1999. 